\title{
AGUA FLORIDA. LUGARES DEL TANGO EN BUENOS AIRES A COMIENZOS DEL SIGLO XX
}

\section{FLORIDA WATER. PLACES OF THE TANGO IN BUENOS AIRES AT THE BEGINNING OF THE 2OTH CENTURY}

DOI: https://doi.org/10.18861/ania.2019.9.2.2950

Dr. Arq. Horacio Caride

ORCID: https://orcid.org/0000-0001-6014-4557 


\section{DR. ARQ. HORACIO CARIDE}

Dcotor en Ciencias Sociales y Arquitecto por la Universidad de Buenos Aires (Argentina). Profesor titular regular de Historia de la Arquitectura y el Urbanismo, Facultad de Arquitectura y Urbanismo, Universidad Nacional de La Plata (Argentina). Profesor titular de Historia del Diseño Industrial y profesor adjunto regular de Historia de la Arquitectura. Miembro del Consejo Académico, profesor y autor del plan estudios de la Maestría en Historia y Crítica de la Arquitectura, el Diseño y el Urbanismo (MAHCADU), FADU UBA (Argentina). Director de Estudios históricos e Investigador principal del Instituto de Arte Americano e Investigaciones Estéticas "Mario J. Buschiazzo" IAA-FADU-UBA. Investigador del Instituto de Historia, Teoría y Crítica de la Arquitectura y la Ciudad HITEPAC-FAU-UNLP. Docente y miembro del Consejo Académico de la Carrera de Especialización en Docencia Universitaria de la FADU UBA. Autor del Programa de Posdoctorado en Historia de la Arquitectura y la Ciudad, FAU-UNLP.

FECHA DE RECEPCIÓN: 10 de agosto de 2019

FECHA DE ACEPTACIÓN: 20 de octubre de 2019

REGISTRO BIBLIOGRÁFICO: CARIDE, H. (2019). Agua Florida. Lugares del tango en Buenos Aires a comienzos del siglo XX. Anales de Investigación en Arquitectura, 9 (2), 45-68. 


\section{RESUMEN}

Este texto trata de algunos lugares de diversión nocturna de una ciudad y de una sociedad de la que apenas quedan indicios. Con preeminencia masculina, su población era en su mayoría inmigrante, desarraigada, en buena medida analfabeta o de escasa instrucción y con un alto grado de precariedad laboral. El aluvión de trabajadores varones que arribaron a Buenos Aires entre fines del siglo XIX y principios del siglo XX se enfrentaron a un proyecto modernizador que no necesariamente los incluía. La noche era una salida obligada que significaba bastante más que un mero esparcimiento. Allí se dieron formas de sociabilidad, donde las academias de baile operaron junto a los despachos de bebidas alcohólicas y bares como antesalas de los prostíbulos.

Palabras clave: Buenos Aires, Noche, Tango, Bajo fondo.

\section{ABSTRACT}

This text deals with some places of nocturnal fun of a city and a society of which there are hardly any indications. With a male preeminence, its population was mostly immigrant, uprooted, largely illiterate or poorly educated and with a high degree of job insecurity. The alluvium of male workers who arrived in Buenos Aires between the end of the 19th century and the beginning of the 20th century faced a modernizing project that did not necessarily include them. The night was an obligatory departure that meant more than a mere recreation. There were forms of sociability, where dance academies operated next to the offices of alcoholic beverages and bars as preludes of brothels.

Key words: Buenos Aires, Night, Tango, Underworld. 


\section{INTRODUCCIÓN}

Este texto trata de algunos lugares de diversión nocturna de una ciudad y de una sociedad de la que apenas quedan indicios. Con preeminencia masculina, su población era en su mayoría inmigrante, desarraigada, en buena medida analfabeta o de escasa instrucción y con un alto grado de precariedad laboral. El aluvión de trabajadores varones que arribaron a Buenos Aires entre fines del siglo XIX y principios del siglo $X X$ se enfrentaron a un proyecto modernizador que no necesariamente los incluía. La noche era una salida obligada que significaba bastante más que un mero esparcimiento. Allí se dieron formas de sociabilidad en espacios particulares, donde las academias de baile operaron junto a los despachos de bebidas alcohólicas y bares como antesalas de los prostíbulos. Los reglamentos generados por el gobierno municipal prohibieron la coexistencia de mujeres, baile y alcohol en un mismo sitio. Sin embargo, los burdeles evitaron con frecuencia las disposiciones que intentaron regular su actividad. Fueron, así, el verdadero centro de un dispositivo nocturno que caracterizó a la capital argentina por décadas. En los prostíbulos, la milonga y el tango iban desarrollándose en sus formas musicales y simbólicas. Ambos marginales por el contacto físico que implicaban y por el contenido de sus letras pero no necesariamente, en términos geográficos, de origen orillero: el bajo fondo tanguero se trasladó desde las orillas al corazón mismo de Buenos Aires, sobre un eje trazado entre la academia de baile y el cabaret. Nuestra intención mirar estos lugares de diversión como parte de una historia urbana y social no demasiado transitada en la bibliografía clásica, que suele abordar esta problemática de una forma segmentada. Buscamos hacer converger algunas miradas históricas, para intentar establecer puntos de partida diferentes. Intentamos, en definitiva, presentar estos sitios, de usos extintos, dentro de su rol de organizadores de territorios urbanos. A través de la doble indagación de sus dimensiones espaciales y sociales, intentamos ejemplificar las mutaciones que sufrió la sociedad porteña en apenas tres o cuatro décadas. ${ }^{1}$

Agua Florida era una versión de Florida Water, un perfume que la empresa Murray radicada en Nueva York, fabricaba desde 1808. A partir de 1861, en sociedad con Lanman \& Kemp, comenzó a exportarlo a varios países. ${ }^{2}$ Se convirtió en una de las fragancias más populares del mundo. Su aroma, básicamente a lavanda, lo hacía una esencia apta tanto para mujeres como para hombres. En Buenos Aires su uso se

1 Dentro de un enfoque general, donde la historia urbana y arquitectónica pretende aportar nuevos elementos para la historia social, esta hipótesis es un desprendimiento de nuestra tesis doctoral y a la vez intenta saldar la deuda de aquella investigación con las arquitecturas del tango (Caride Bartrons, 2017).

2 Lanman \& Kemp-Barclay and Co. Inc. http://floridawater1808.com (consultado el 07-05-2018). 
dilató en los ámbitos rural y urbano (Inchauspe, 1942: 43; Arlt [1929] 2013: 34). Un tango le rendió homenaje con el mismo nombre. Fueron sus imágenes las que organizan este relato.

\section{VOS ERAS CRIOLLA}

Agua florida, vos eras criolla.

Te usaban las pobres violetas del fango

de peinados lisos, como agua'e laguna,

cuando se bailaba alegrando el tango

con un taconeo y una media luna.

Perfume del tiempo taura que pasó, pues todo en la vida ha de ser así, cuando las percantas mentían que no mientras las enaguas batían que sí.

Chinas sencillas y querendonas, que al son de las acordeonas bailaban un milongón;

Chinas que oliendo a agua florida se metían en la vida

a punta de corazón.

Agua florida vos eras criolla.

De cuando una viola tocaba de prima y otras las cuarteaban dando a las bordonas, y un ramo de taitas era cada esquina y la vida era linda y guapetona.
Vos eras del tiempo del gacho ladeao,

de la mina airosa anclada al bulín,

del lazo en el pelo, del percal floreao,

de la academia y el peringundín. ${ }^{3}$

La letra que trascribimos es de 1928. Más popular fue la versión de Ángel Vargas, con la orquesta de Ángel D’Agostino, registrada por la Victor en 1941. Fue una adaptación del tango que los uruguayos Fernán Silva Valdés (letra) y Ramón Collazo (música), habían estrenado para el mismo sello y cantada por Alberto Vila en 1928. ${ }^{4}$ En la interpretación de Vargas y D’Agostino, la introducción orquestal, repite el verso "Agua florida, vos eras criolla" pero al final omite las últimas dos cuartetas. Aun dentro de un mismo territorio cultural, estos cambios -bastante frecuentes- pudieron obedecer a diferentes razones. Los tangos tenían cierta vida propia, intervenidos por distintos autores hasta que se fijaba su acta de nacimiento en la partitura. En principio, no se trataba simplemente de una traducción rioplatense, para hacer más comprensible una historia de Montevideo en el ambiente porteño. ${ }^{5}$ Durante la

3 Todas las letras de los tangos citadas en este texto provienen del sitio web Todotango, declarado de Interés Nacional, http://www.todotango.com/ (consultados el 12-03-2018).

$4 \quad$ Ambas composiciones consiguieron su máxima consagración interpretadas por Carlos Gardel.

$5 \quad$ Esto sucedió, por ejemplo, con el tango Garufa (1927), con letra de Víctor 
década de 1940, algunas veces se recortaron las letras de tangos más antiguos para dar un mayor protagonismo a la melodía y lograr así una música más bailable. Pero los motivos de la ausencia pudieron ser también la necesidad de estilización y control sobre referencias incómodas en las letras originales de los primeros años del siglo XX. ${ }^{6}$ Reproducidos años después, la censura es un hecho comprobable, por recorte o directamente por un cambio completo de lenguaje y composición (Varela, 2016: 19-20; Caride Bartrons, 2017: 216217). En Agua Florida, en la primera de las estrofas omitidas, resultaba inconveniente la alusión al taita, denominación lunfarda de matón y prepotente, que podía estar asociada sin demasiado esfuerzo al proxeneta: "Oh! callejón de turbios caferatas que fueron taitas del mandolión! ¿Dónde estará mi garsonier de lata, bulín mistongo que fue mi perdición?". ${ }^{7}$ La

Soliño y Roberto Fontaina y música del propio Collazo. De los mismos autores, integrantes de la Troupe Ateniense, Mocosita (1926), supo tener una anterior "letra canalla" (Soliño, 1967, p.11). 6 Por ejemplo Los dopados (drogados o narcotizados en el argot lunfardo), tango instrumental de Juan Carlos Cobián para la obra teatral homónima, tuvo una primera letra de Raúl Doblas y Alberto Weisbach (1924) que mantuvo el espíritu original pero varió de adicción. Fue reemplazada en 1942 por Enrique Cadícamo con un título menos controvertido: Los mareados.

7 Del tango Viejo Rincón, letra de Roberto Lino Gayol (1925). La expresión "caferata" es uno de los tantos sinónimos idea de "una mina airosa anclada a un bulín" o garçonnier (departamento reservado a citas amorosas), podía referirse a la prostituta del lupanar que ascendía en esta escala social asumida como una mantenida, es decir, la querida de un sólo hombre en la cúspide de la pirámide prostibularia. La descripción de todo el ambiente de repudio y la explotación fue sintetizada Roberto Arlt en Los siete locos, publicado un año después:

La mantenida desprecia a la mujer de cabaret, la mujer de cabaret desprecia a la yiranta, la yiranta desprecia a la mujer de prostíbulo, y, cosa curiosa, así como la mujer que está en un prostíbulo elige casi siempre como hombre a un sujeto de avería, la de cabaret carga con un niño bien o un doctor atorrante para que la explote (Arlt [1929] 1997: 39).

Más directas aún, son las referencias de la última estrofa. El peringundín resultaba el lugar más representativo del bajo fondo rioplatense, una versión criolla de un antro de mala muerte. Por otro lado, la academia de baile, era un nombre posible para los prostíbulos encubiertos, que operaban fuera del régimen de tolerancia de Buenos Aires entre 1875 y 1936.

Los lugares del tango, como sus letras y sus modos de baile, sufrieron estas mutaciones necesarias en el paso de la marginalidad a la consagración. Pero más que una sustitución, se trató de una solapada convivencia. En esas seis décadas, la sociedad de Buenos Aires,

que el lunfardo usó para denominar a un explotador de mujeres. 
cambió, se transformó y reconfiguró en función de diferentes avatares económicos, regímenes políticos y, en definitiva, paradigmas culturales. El modo de vida de los porteños, la esfera de lo privado, las relaciones con el espacio público y los vínculos entre el centro y los bordes urbanos a comienzos de la década de 1940, eran muy diferentes a los de la época del Centenario e incluso, a los de la década de 1920. De esta manera, debemos ir a las últimas décadas del siglo XIX para precisar un origen del ciclo que pretendemos interpretar.

\section{EL TIEMPO TAURA}

Agua florida era un símbolo del tiempo taura, es decir, una época y un territorio de compadritos, audaz pero con connotaciones de marginalidad. Se refiere a ciertas áreas de la ciudad y sus alrededores, donde la ley llegaba tarde o nunca. La imprecisión de una época y de un lugar para el Salón de Julia, ambiente imaginado por Jorge Luis Borges en Hombre de la esquina de rosada, resulta una referencia conveniente e inevitable. El cuento, con una versión original de 1927, es representativo de estos lugares de diversión nocturna, mezcla de despachos de bebidas, salón de baile, garitos y prostíbulos (Mazzucchelli, 2016: 6; Rocca, 2010: 2). En el relato aparece una ruralidad manifestada en el lenguaje, en el ambiente y en las conductas. Estos detalles permiten suponer que se trataba de un boliche de la ribera porteña hacia fines del siglo XIX. Mientras los reglamentos municipales y los edictos policiales buscaron siempre separar estas actividades con el fin de preservar determinado status moral, los espacios donde se desarrollaban se mezclaban, indefinidos, en usos y emplazamientos. El tango y la milonga cantados y bailados, fueron adquiriendo forma dentro de estos lugares inciertos, antes de conquistar espacios centrales, en términos territoriales y simbólicos.

Desde 1875, la policía contaba con un Reglamento de Prostíbulos de origen municipal, como principal instrumento normativo para actuar ante los posibles escándalos públicos provocados en los burdeles de la ciudad. Parte del artículo $10^{\circ}$ contemplaba las pautas de conductas para las prostitutas:

(...) No podrán mostrarse en la puerta de calle, ni en las ventanas o balcones de la casa que ocupen, ni llamar a los transeúntes o emplear cualquier género de provocación, lo que les será prohibido hacer igualmente en las calles, paseos públicos y teatros, no pudiendo concurrir a éstos en traje deshonesto (Bilbao, 1926: 14).

Se trataba evidentemente de un control urbano para zonas consolidadas de la ciudad. El reglamento se había hecho para un centro celebrado, que había que preservar en términos morales, cuando no defender de una verdadera amenaza que provenía de los suburbios. En aquellos parajes periféricos, la realidad era otra. Ninguna expresión nacida en semejantes circunstancias podía ser admitida como parte de la cultura nacional. Así, el tango fue para algunos intelectuales “(...) un reptil de 


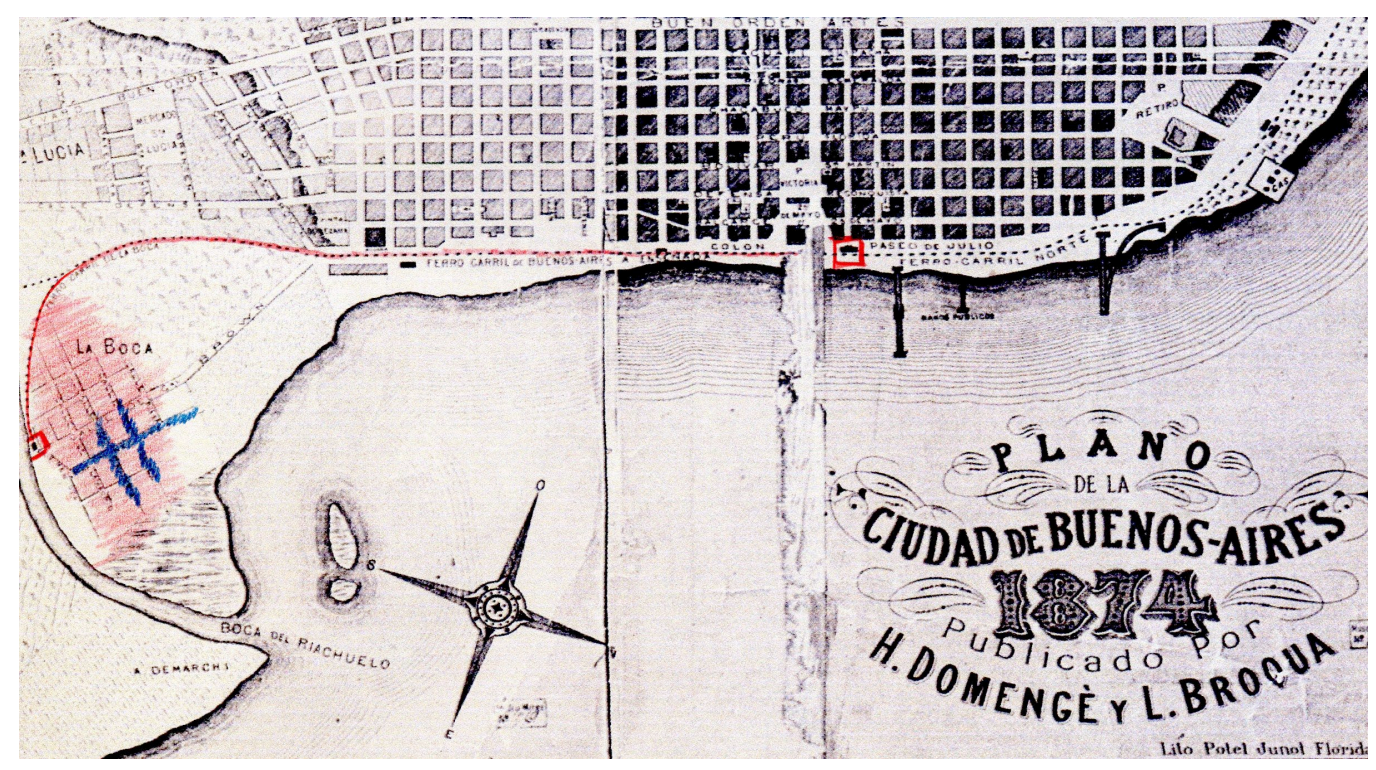

Figura 1.

El barrio bajo de La Boca y su conexión con el centro, con indicación de las calles de mayor con mayor concentración prostibularia durante la década de 1880 .

lupanar, tan injustamente llamado argentino en los momentos de su boga desvergonzada" (Lugones, 1916:117). De esta primera época del tango prostibulario, aquellos territorios de baja legalidad eran los continentes de un desorden moral que llama a las puertas de la ciudad decente, muchas veces de la mano de jóvenes de clase alta.

La condición semirural y cercana a los bordes fluviales de los barrios de Barracas y especialmente de La Boca instaló a la zona, más allá de su condición topográfica, en el imaginario porteño como barrios bajos por su decadencia moral. Durante las últimas dos décadas del siglo XIX, el movimiento de mercancías y de personas en el puerto del Riachuelo, iba a transformar toda el área, convirtiéndola en uno de los suburbios más animados de la ciudad. El Ferrocarril de La Boca, que comenzó a funcionar en 1866, la comunicaba con la Plaza de Mayo, con trenes que partían de la Estación Central -contigua a la Casa Rosadarecorriendo la costa hasta una estación en la Vuelta de Rocha, al borde del Riachuelo (Figura 1). Para 1880, la Memoria del Departamento de Policía (en adelante MDP) de la recién creada Capital Federal, indicó la presencia de sólo dos prostíbulos regulados, uno sobre la calle Suárez y otro sobre la calle Brandsen (MDP, 1880-1881, p.227- 231). Pero en 1887 se habían habilitado veinte casas de tolerancia 
sólo aquel año. Para 1894, la Memoria del Intendente Municipal (MIM) sostenía que había en la zona entre ochenta y cien prostíbulos clandestinos, en general regenteados por italianos. La mayor concentración, estaba sobre las calles Necochea, Suárez y Brandsen. (MIM, 1893-1894:173-175).

A comienzos del siglo XX, la esquina de Suárez y Necochea era el epicentro de fuerzas que sacudían la noche de los suburbios, poblada de marineros borrachos, políticos en ascenso, pitucos en busca de diversión, prostitutas y maleantes de diferente pelaje. En pocos metros convivían los cafés, los bailongos, las cantinas y los burdeles. Gardel los cantó en Aquella cantina de la ribera, con letra de José González Castillo, en 1923.

\footnotetext{
Rubias mujeres de ojos de estepas,

lobos noruegos de piel azul,

negros grumetes de la Jamaica,

hombres de cobre de Singapur.

Todas las pobres almas sin rumbo

que aquí a las playas arroja el mar,

bajo los cuatro vientos del mundo

y en la tormenta de una jazz-band.
}

En dos cuartetas, la letra revelaba orígenes, historias, sueños y fracasos. Allí estaban, entre otros, el Café Royal, Lo del Griego y el Café Concert. Este último era un "café de camareras", versión porteña de una moda parisina que alcanzó su mayor difusión durante la segunda mitad del siglo XIX. A su pequeño escenario subieron varios músicos y cantantes, como Ricardo Brignolo, Agustín Bardi o Angel Villoldo. También se representaban en él algunas obras de teatro (Puccia, 1976: 190191). En La Marina, sobre la calle Suárez hizo su debut Roberto Firpo.

En 1908, el tramway eléctrico del norteamericano Charles Bright, unió La Boca con Palermo, lo que significó un nuevo impulso para la zona. De ese año es el café Las Flores que expandió el territorio nocturno del barrio sobre la calle Pedro de Mendoza, más cercano a la estación del ferrocarril, frente al Riachuelo. Las Flores, también fue un café de camareras. Con ese nombre lo hizo famoso la única novela que escribió Enrique Cadícamo. Entre los numerosos locales que ofrecía la noche de La Boca, lo consideró como un antepasado “(...) de lo que muchos años más tarde se llamó con la misteriosa denominación de cabaret". Por otro lado y ante una gresca de dos prostitutas taqueras (callejeras), el encargado del mostrador se encargó de separarlas mientras gritaba que el lugar era un café de camareras y no un peringundín de la Recova (Cadícamo [1969]1973: 42; 65). En estas dos alusiones, el célebre poeta del tango revelaba algo de la secreta genealogía de los lugares de la noche porteña y sus variantes tipológicas.

Es posible que el adjetivo "misterioso" aplicado por Cadícamo al cabaret también haga referencia al amplio espectro de espacios y actividades que se describían bajo aquella 

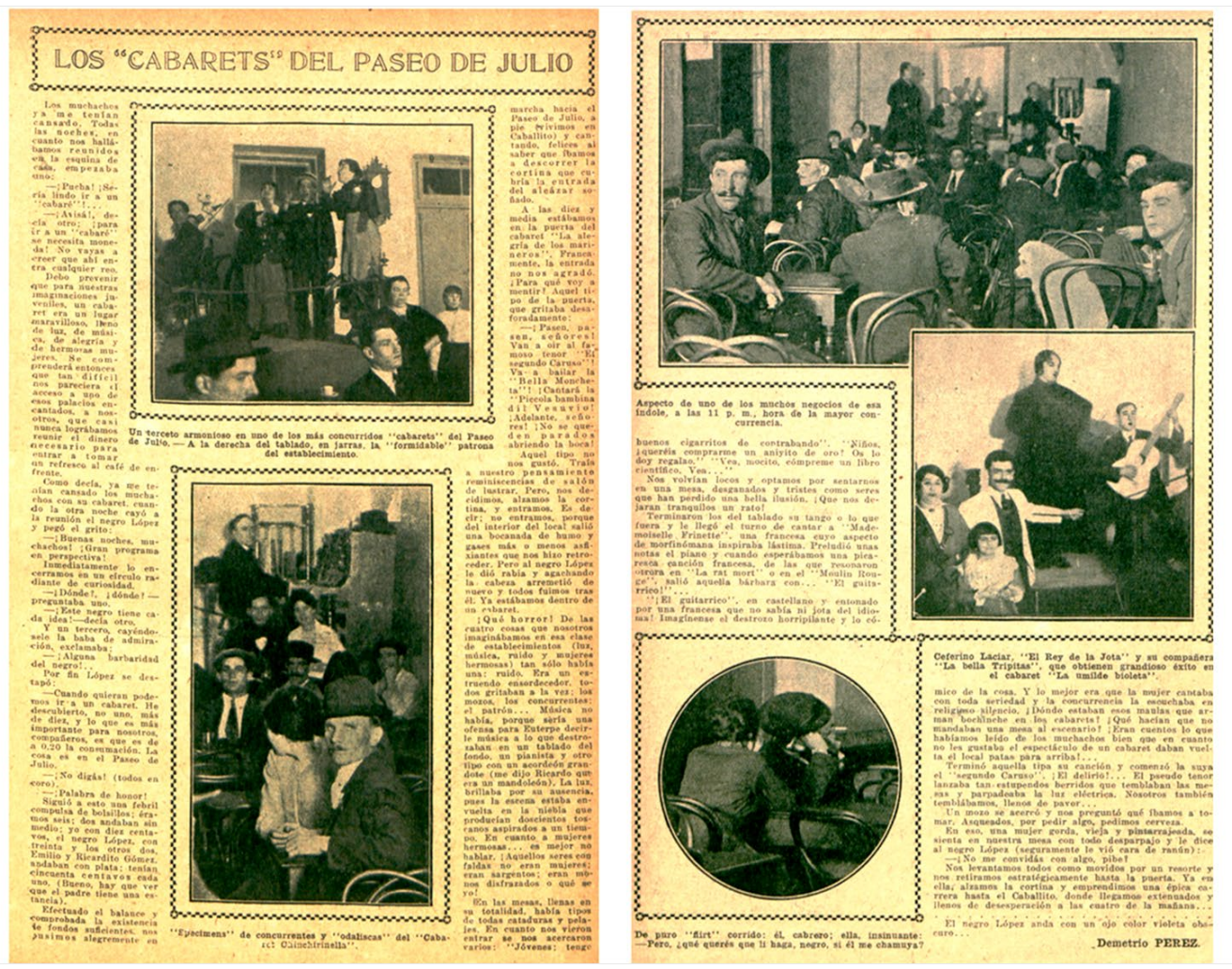

Figura 2.

Imágenes del "cabaret" - un peringundín- "La Umilde Bioleta", ubicado en La recova del Paseo de Julio, publicadas en Fray Mocho en 1916

denominación. Muy difíciles de catalogar, incluía hacinados antros del Paseo de Julio, como La Umilde Bioleta (Figura 2) hasta los lujosos salones de baile de las décadas de 1920 y $1930^{\circ}$. En un extremo figuraba el cabaret, como la expresión más sofisticada de la puesta en escena prostibularia. En el otro, el peringundín, como un eslabón inclasificable en la cadena de locales nocturnos de la ciudad, integrada por los cafés de camareras, cafés cantantes, orquestas de señoritas, bares de coperas, amuebladas, casas de confianza, de citas o posadas, casas de tolerancia, quilombos o burdeles clandestinos, cines pornográficos y academias de bailes.

8 Agradezco a Gustavo Varela la información sobre esta publicación. 


\section{LA ACADEMIA Y EL PERINGUNDÍN}

En menos de una generación, esta cultura de los suburbios, con el tango entre sus expresiones más representativas, llegó al centro para compartir un mismo espacio con otros bailes tradicionales. Una especie de "contaminación" de las orillas había alcanzado a los barrios respetables (Sarlo, [1988] 1999: 179). Mientras sus letras fueron disimulando ese "origen infame", con el que le gustaba provocar Borges, su baile recibió una paulatina aprobación pasando de la indecencia a la elegancia.

La difusión del tango en ciertas ciudades de Europa y de los Estados Unidos, puede servir de espejo donde mirar la complejidad social de sus lugares y de sus territorios urbanos. Tempranamente -durante la primera década del siglo XX- el baile rioplatense fue reconocido como un producto de exportación de alto nivel. Se lo aceptó en los elegantes salones de Londres, París o Nueva York, admitido en las reuniones de la alta sociedad como una práctica de sus pares argentinos (Matallana, 2016: 2425). Tal afirmación expone una relación entre el tango y la clase alta que resulta previa a su éxito europeo (Varela, 2016: 74). No obstante, $y$ al menos en algunas ciudades de los Estados Unidos, el mismo sector social que lo había dignificado, a comienzos de la Gran Guerra, lo consideró una práctica pública indecente. Vinculado en definitiva a los bajos fondos urbanos, particularmente a los de Nueva York, la prensa acabó por criminalizarlo. Aún así, en un movimiento pendular, ya bien entrada la década de 1920, los bailes de caridad de la alta burguesía, vuelven a glorificar al tango argentino como una de sus más sofisticadas propuestas (Matallana, 2016, p. 57; 66; 71; 8889). Esta mirada externa, en la complejidad de un ciclo de aprobación y condena, acaso refleje el amplio espectro de lugares donde el tango se bailó en Buenos Aires y la diversidad de los grupos sociales que abarcó.

Que una academia de baile era en realidad el nombre que designaba a un prostíbulo, era un asunto conocido. Lo suficiente como para impedir el ingreso a los miembros de la recién creada Policía de la Capital. Por el artículo 56 del Primer Proyecto de Reglamento de Policía de 1880 , se prohibía a los agentes en servicio la participación en cualquier clase de diversión pública “(...) y fuera de él, tampoco podrán hacerlo en aquellas de carácter público y honestidad dudosa, como los bailes en academias o las máscaras en los teatros". La pena por infligir esta norma podía ser la suspensión o incluso la destitución (MDP, 1880-188: 65). El hecho de formar parte del articulado de una regulación institucional tan genérica, hace suponer que estas academias y sus actividades de "honestidad dudosa" no habían aparecido de la noche a la mañana y, probablemente, eran burdeles clandestinos años antes de que en ellas se bailara el primer tango o la primera milonga. No obstante, es evidente que el contacto corporal de los nuevos ritmos contribuyó a su fama prostibularia. 
Ese mismo año, la primera jefatura de policía a cargo de Marcos Paz, elaboró un Reglamento para bailes públicos. Por él se prohibía los bailes en posadas y casas amuebladas, es decir, en los hoteles frecuentados por prostitutas pero que no vivían en ellos, conocidos como "casas de citas". La norma no menciona a las casas de tolerancia, cuya regulación la precedía en cinco años. Tampoco se permitía consumir alcohol en los lugares de bailes, ya que el objetivo era “(...) limitar el número de estas casas, que no satisfacen ninguna necesidad legítima de la población". (MDP, 1880-1881: 119 y 120; MDP 1881-1882: 12). Así, quedaba establecido el grado de separación entre una clase dirigente, que asumía un modelo de control espacial y social para la nueva ciudad y las posibilidades concretas de aplicarlo. Del mismo modo, el accionar del personal subalterno era cuestionado puertas adentro por la misma dirigencia institucional. En diferentes tramos de las Memorias Policiales, se anota la dificultad para controlar la corrupción de los agentes que permitían los bailes ilícitos y el conflicto que estas regulaciones presentaban con la garantía constitucional del derecho de reunión. Todas las crónicas de visitantes, curiosos o clientes confesos de los primeros años del siglo XX, declararon que en los prostíbulos de Buenos Aires, especialmente en los de primera categoría, se bailaba (casi siempre) y se consumía alcohol (siempre).
Así, desde las últimas dos décadas del siglo XIX, no resulta sencillo definir los límites territoriales del prostíbulo, el despacho de bebidas o el café y la academia de baile. La mujer prostituida asumía la función de camarera o de eventual pareja de baile. Los diferentes roles se improvisaban en la clandestinidad, que exigía la interpretación de estos papeles $u$ otros, con el fin de sortear las regulaciones de salubridad, la observación de determinadas conductas y los pagos impositivos. Pero antes de finalizar el siglo XIX, algunas milongas y tangos andaluces se subieron a los escenarios reales y formaron parte de dramas criollos e incluso de alguna zarzuela, "bailados con coreografía orillera" (Casadevall, 1957, p. 13).

Las fiestas carnaval constituyeron el momento de mayor algarabía para la población... y un problema para el control social por parte de las autoridades policiales. El Reglamento para bailes de 1881, relajaba los horarios y la frecuencia durante aquellos días. Además de los domingos de 18 a 24 horas, autorizaba bailes de máscaras hasta las tres de la madrugada y extendía el permiso a los días festivos y sus vísperas (MDP, 1880-1881, p.120). Era el momento del año donde las meretrices hacían el mayor gasto en ropas, maquillaje y perfumes. Preparadas para la ocasión, “(...) estas veinte o treinta mil prostitutas se dividirán en los distintos sitios de academias y teatros (...)" (Batiz, [1908] c.1960, p.81). Aunque el cálculo del subcomisario Adolfo Batiz puede resultar exagerado, da una idea de la magnitud del clima 
instalado en el imaginario social ${ }^{9}$. Más allá de la veracidad de las cifras, los bailes de carnaval eran vistos en su conjunto como un momento de descontrol urbano. En 1885, el entonces jefe de policía, Francisco Bosch, le solicitó por vía oficial al intendente Torcuato de Alvear la suspensión de los bailes de disfraz de febrero de aquel año. Argumentaba que la celebración de un proceso eleccionario y las festividades eran un motivo más para el desorden público. El mismo día, el intendente respondió afirmativamente (MDP, 1885-1886: 71-72).

En 1881 en el radio comprendido entre las calles Salta y Chacabuco y las avenidas Rivadavia e Independencia (unas cuarenta manzanas), había unos treinta burdeles regulados (MDP, 1880-1881:187-188; 231). Pero las redadas habituales hacían sospechar que en sus más de noventa cafés, fondas y bodegones se ocultaban muchos prostíbulos y salones de baile clandestinos. Las actividades ilícitas, que comprendían garitos, bailes y el consumo de bebidas alcohólicas y de estupefacientes, se desarrollaban en dependencias traseras. En este sentido, el tema de las drogas y su relación con el ambiente del tango en Buenos Aires permanece como un tabú en nuestra historiografía. Sin embargo, es dable

9 Guy Burdé estimó que en Buenos Aires vivían en 1880 unas 338.000 personas. Suponiendo un $50 \%$ de mujeres y excluyendo a las niñas menores de 12 de años, el valor menor de 20.000 prostitutas que supone Batiz representaba como mínimo el $12 \%$ de las mujeres de la ciudad. suponer el consumo de alucinógenos en un lugar impreciso entre la prescripción médica y la adicción, ya desde fines del siglo XIX. Su disponibilidad está documentada. En el Manual del laboratorio Merck de 1899, figuran drogas como la cocaína y el opio para el tratamiento de alcoholismo y su uso terapéutico en diferentes dolencias. La cocaína como hidroclorato se encontraba en polvo o en cristales y, entre los opiáceos, cuatro variantes de morfina: cristales puros, hidroclorato, meconato y sulfato (Merck, 1899: 29; 51; 94). Es posible que la palabra del lunfardo merca, una de cuyas acepciones designa genéricamente a las drogas ilegales, tenga su origen en el nombre del laboratorio.

La Memoria Policial menciona el uso de timbres eléctricos disimulados en los mostradores de los locales que daban a la calle, para alertar a los concurrentes de las habitaciones interiores sobre la presencia de la policía. Algunos de estos locales estaba revestidos con colchones para evitar que el sonido de la música se escuchase desde el exterior (MDP, 1880-1881, p.187-188). El silencio y el espacio secreto eran condiciones necesarias para la existencia de muchos de estos sitios. En 1913, la regulación municipal tuvo que volver a expedirse sobre los alcances del concepto de "escondrijo", que aparecía "interpretable" en una ordenanza de 1907. El asesor legal de la Municipalidad, José Capdevilla, debió aclarar que se trataba de un lugar en el que se podía esconder una o varias personas, al que se accedía por una puerta disimulada con algún mueble, en un sótano $u$ 
otra habitación oculta (Bilbao, 1926: 180-181).

La forma más difusa de una actividad ilícita era el peringundín, noción polisémica que resiste bastante la indagación de sus espacios y disposiciones. La palabra, "peringundín” (o "piringundín") es de origen incierto. Más allá de la mitología y de las anécdotas que rodean su significado, la mayoría de los exégetas del lunfardo coinciden en que es un vocablo que proviene de algún dialecto italiano recreado en el Río de la Plata. Tal vez provenga del napolitano o del genovés como deformación del francés perigordin, un tipo de danza del Perigord. Era básicamente un lugar para gente de "moral dudosa". Con la apariencia diurna de un humilde café, su vida nocturna reunía un variopinto elenco de personajes, que podían disponer de habitaciones traseras, no siempre reconocidas por las regulaciones municipales. En general su desarrollo y expansión estuvo vinculado a la inmigración italiana, de la que probablemente vino el apelativo. Pero el peringundín, podía estar o no estar. Es decir, podía ser un lugar indeterminado y "comenzar" a partir de la voluntad de los asistentes. A finales de la década de 1930, la milonga La cepillada, de Manuel Romero, propuso
En tanto evidente posibilidad espacial, también podía considerarse como una categoría ideológica. En el local se despachaban bebidas y algún tipo de comida. Incluso podía ofrecer un precario hospedaje. Terminar allí la noche a los golpes resultaba habitual. Nuevamente Manuel Romero, apelaba a un recuerdo en Carnaval de antaño:

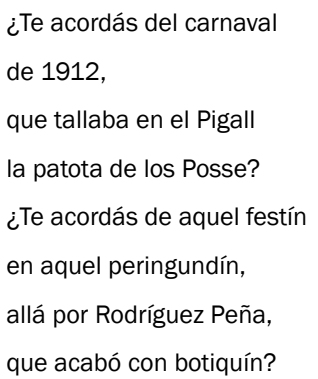

Rodríguez Peña es una calle del centro de Buenos Aires, paralela a la avenida Callao: los peringundines, en sus diferentes categorías, aparecían por toda la ciudad consolidada. Aún así, vimos que uno de los personajes de Cadícamo en Café de camareras, les aclaraba a dos prostitutas que Las Flores no era "un peringundín del Bajo". En efecto, la mayor concentración de peringundines se dio en el Bajo, en los bordes del centro y cercano al Río de la Plata. A fines del siglo XIX, el movimiento de personas de ferrocarriles y de barcos en la zona se concentraba en la Estación Central y el Muelle de Pasajeros, lugar de transferencia vinculado a la relativamente cercana Estación del Parque, donde hoy está el Teatro Colón, en Plaza Lavalle (Figura 3). Protegidos por 
las extensas recovas del Paseo de Julio, que antes de comenzar la década de 1920 se Ilamó avenida Leandro N. Alem. Mezclados con lugares donde se vendía pornografía, la mayoría funcionaban como pequeños prostíbulos encubiertos..

El escritor Roberto Arlt la llamó “la recova canalla", aquella donde Jorge Luis Borges ambientó el cuento "Emma Zunz" (Caride Bartrons, 2015: 39-41) (Figura 4). Con los años, el bajo fondo amplió su territorio y se extendió a las calles cercanas, especialmente 25 de Mayo, la primera paralela al Paseo de Julio, subiendo por la barranca

No obstante, algunas casas de tolerancia de gran tamaño, con quince habitaciones o más, que se habían instalado en la zona antes de que se negasen nuevas habilitaciones de prostíbulos en 1925, funcionaron hasta la ilegalización de 1936. En general el peringundín era el local a la calle en la planta baja, donde las prostitutas alternaban y bailaban con los clientes. Solía ser el acceso principal del burdel (Caride Bartrons, 2017a: 230-235). Durante horas de la tarde había café y alguna comida sencilla. La noche, donde imperaba el alcohol, podía continuar en algunos de los cuartos disponibles en los pisos altos.

Dentro de este discurso, los territorios del pecado, los bajos fondos morales, están en algún lugar "donde el barro se subleva”, según aventuró Cátulo Castillo décadas después. Sin embargo, ya hemos adelantado que estos bajos

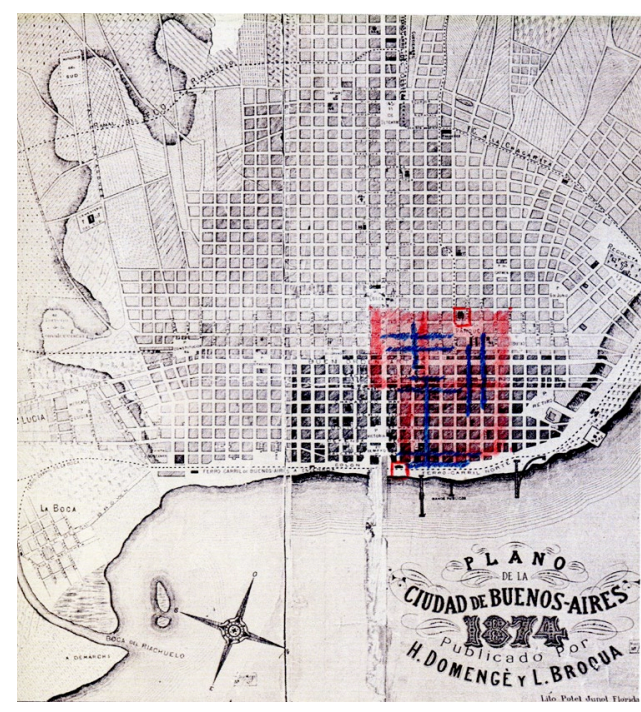

Figura 3.

El barrio de San Nicolás con indicación de las estaciones de ferrocarril Central y del Parque y de las principales calles prostibularias 


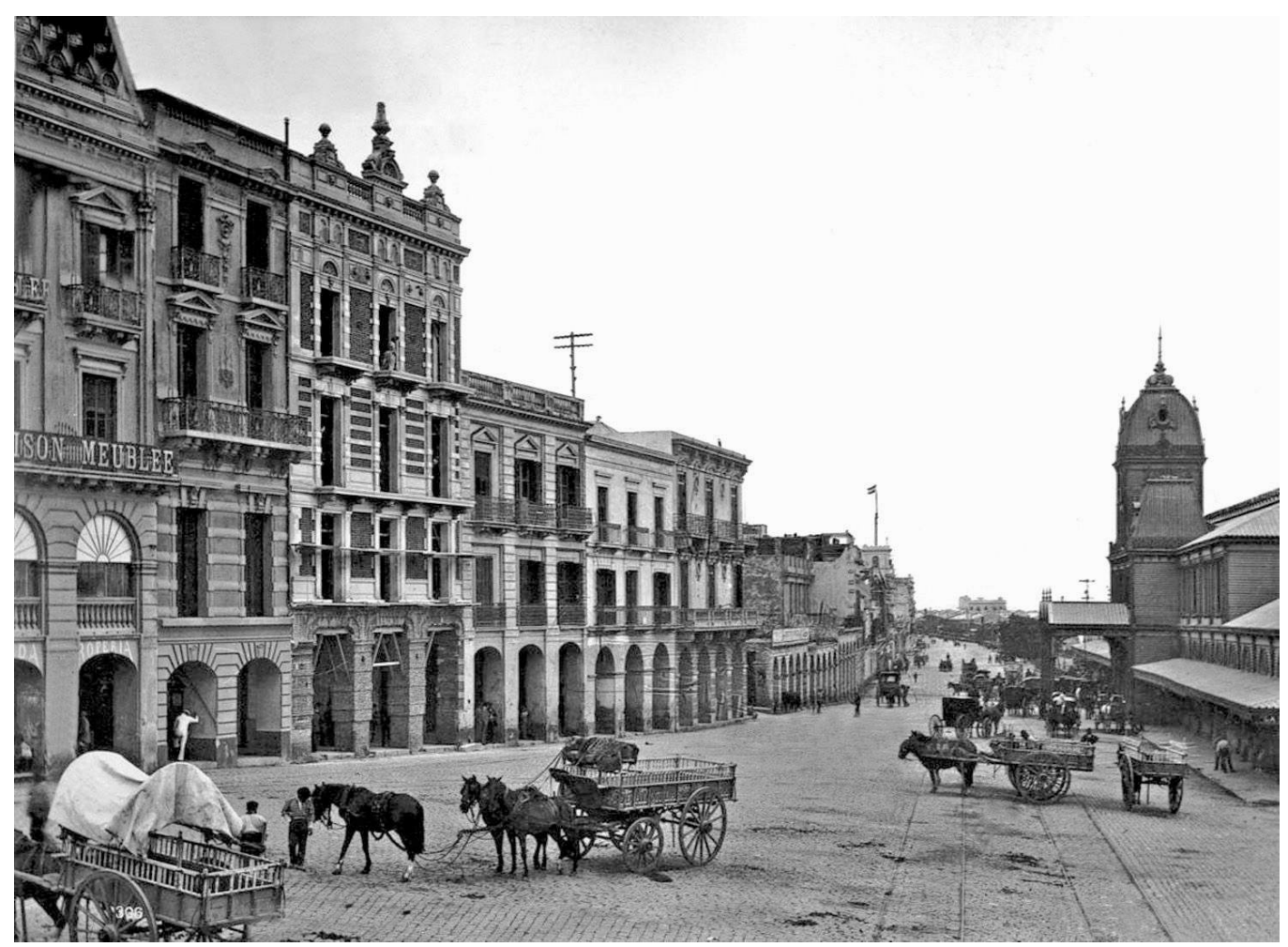

Figura 4.

El comienzo del Paseo de Julio, la "Recova Canalla" y la Estación Central de Buenos Aires hacia 1895

fondos morales no fueron únicamente orilleros.

La idea de un tango, en su procedencia gestado y bailado en los bordes de la ciudad, debe ser contestada con la posibilidad de verlo en los prostíbulos como espacios representativos de la noche porteña. Desde finales de siglo XIX ya se habían instalado en lugares céntricos de la ciudad y allí permanecieron, bajo diferentes denominaciones.

\section{VIOLETAS DEL FANGO}

En la construcción de estas metáforas del bajo fondo, verdaderas constelaciones de significados, el barro y el agua engendran vida a través de plantas y flores, éstas últimas inevitablemente asociadas a la figura femenina. ${ }^{10}$ En tanto representación del

10 En la tesis doctoral de Mario Sabugo, el concepto "constelación" adquiere una dimensión operativa que permite acceder al complejo universo de

60 Anales de Investigación en Arquitectura Vol.9 (2), 2019. Montevideo (Uruguay), 45-68 
relajamiento moral de una mujer, tal vez su mención más emblemática sea Flor de Fango, de Pascual Contursi (1917). Según Mario Sabugo, dentro su pormenorizado estudio de los imaginarios del habitar a través de las letras del tango, “El fango aloja multitud de significados: es la fertilidad, es el pecado, y también es la injusticia, y entonces el fango material se convierte en el fango social" (Sabugo, 2013: 232).

De la numerosa oferta de lugares de diversión nocturna de Buenos Aires, el gran protagonista fue el cabaret. En él “(...) se codeaban el ruidoso libertinaje y la curiosidad, (...) jóvenes de altas clases, sus queridas, curiosos y algunas muchachas “de la vida' que acuden solas (...)", anotaba Manuel Gálvez en la primera página de Nacha Regules. "El tango, casi exclusivo allí, y la orquesta típica, instalan, entre la champaña y los smokings, el alma del arrabal" (Gálvez, [1919] 1933: 5). La imagen del lujo, representada por las bebidas y las vestimentas costosas, se pone en tensión con el espíritu orillero. Con esta composición, el cabaret (o cabaré) llegó a ser el más refinado de los prostíbulos porteños.

El Royal Pigall, se ubicaba en la calle Corrientes 865, entre Suipacha y Esmeralda, predio en el que luego del ensanche de Corrientes, se levantó el teatro Tabarís. Un "antro de perversión y escenario de orgías desenfrenadas, en el

metáforas, símbolos y significados de los imaginarios del tango (Sabugo, 2013). que las flores de fango iniciaban el trágico camino que fatalmente desembocaba en el hospital" (Soliño, 1967: 5). La referencia al hospital que hace Soliño puede tener algunas interpretaciones. ${ }^{11}$ De todas maneras, la imagen es complementaria a las historias moralizantes, cuando las letras del tango advierten que el final de una cabaretera es siempre dramático:
Cuando eras una papusa
y andabas bien empilchada,
eras la paica mimada
que a tu capricho reinabas.
A los hombres los tratabas
con el desprecio más rudo,
y más de un viejo platudo
por tu culpa se arruinó.
Del cabaret te espiantaron
y te prohibieron la entrada,
se te acabó la parada
te perdiste en el olvido.
$\mathrm{Y}$ un miserable vestido
tuvieron que regalarte,
pues causa pena mirarte
de pobrecita que estás.

11 Una prostituta hospitalizada quizás indicaba la brutalidad de las golpizas de los explotadores de mujeres de las diferentes clases sociales, que también había denunciado Arlt. Pero tal vez aludía al riesgo de contraer alguna enfermedad venérea, sin posibilidades de cura hasta la producción masiva de la penicilina a comienzos de la década de 1940. 
En Entrada prohibida, la letra Germán Teisseire escrita en 1916, describe el triste final de una "paica", es decir, de una amante o mantenida de un solo hombre que también podía considerarse explotada por un rufián.

Todos los cabarets de Buenos Aires de comienzos del siglo XX, como el Royal Pigall, podían devenir en prostíbulos, en la medida en que la cantidad de dinero fuera suficiente. Una anécdota, relatada por sus protagonistas, revela a los "niños bien" como la línea que conectó el tango prostibulario con los espacios de diversión frecuentados por las sectores sociales más elevados. "La noche recién empieza, muchachos. Hay que prolongarla con buenos tangos en el Royal. Yo invito", sentenció Martín Máximo de Alzaga Unzué (“Macoco”), a comienzos de la década de 1920. Según el propio de Alzaga, él y un grupo de amigos hizo expulsar del local a otros asistentes. Le solicitó a Emilio Fresedo Que polvo con tanto viento, un tango instrumental de Pedro Quijano (c. 1890), de conocido origen prostibulario. El director de orquesta no lo ejecutó, alegando la ausencia en su repertorio. Propuso otras alternativas, mientras la fiesta se organizada con "todas las chicas" presentes, (Alifano, 2011: 76-77). El cabaret era funcional a los requerimientos del poder de la más alta clase social porteña, pero no era su lugar exclusivo. Los clientes que pidió desalojar "Macoco" seguramente no pertenecían a su status, porque “(...) estaban además -y esa era la salsa del cabaret- las barras de los habitués. La de los bacanes y la de los patos". Es decir, los ricos ("bacanes") y los que claramente no lo eran ("patos"), según la descripción que Víctor Soliño hizo de la concurrencia del Royal Pigall, en aquellos años (Soliño, 1967: 6).

El Armenonville Les Ambassadeurs, estaba en la continuación de la avenida Canning (hoy Jerónimo Salguero) y Centenario (avenida Figueroa Alcorta). Se inauguró en 1927, obra del arquitecto Valentín Brodsky. Según la empresa constructora, se levantó en menos de tres meses, record que evidenciaba los recursos que podían llegar a movilizar este tipo de actividades (Figura 5).

A menudo se lo veía a Juan Carlos Cobián tocando el piano y también lo hicieron famoso las actuaciones de Carlos Gardel. A finales de la década de 1920, el grado de aceptación del tango ya era indiscutible $\mathrm{y}$, acaso como reflejo de lo que estaba sucediendo en varias ciudades de Estados Unidos, el refinamiento de la decoración del salón principal recordaba las ornamentaciones de los set del cine de Hollywood.

Según Francisco Canaro, los grandes jardines que lo rodeaban eran una de sus mayores atractivos durante los veranos. En el interior, además del salón para las actuaciones, con mesas y sillas para un numeroso grupo de asistentes había “(...) saloncitos reservados y confortables para quienes deseaban ocultar sus canitas al aire o la discreción de soledad 


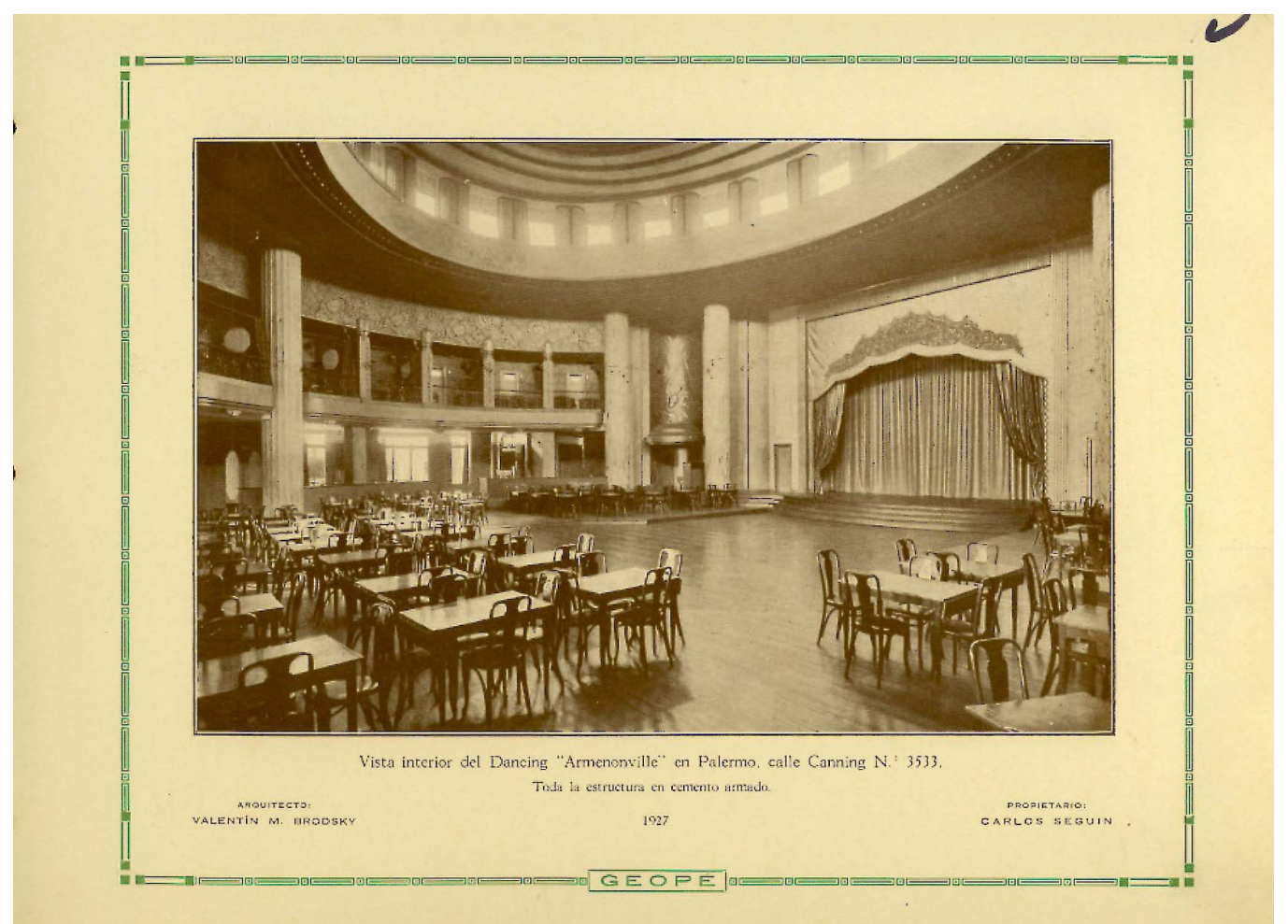

Figura 5

Gran salón del cabaret Armenonville Les Ambassadeurs, en su inauguración en 1927.

de dos en compañía (Pujol, 1999: 111). La noche podía continuar en otros lugares, de los cuales el cabaret había sido antesala. En 1928, al año siguiente de la inauguración de Les Ambassadeurs, Enrique Santos Discépolo compuso Esta noche me emborracho.

Sola, fané y descangayada,

La vi esta madrugada

Salir de un cabaret.

Flaca, dos cuartas de cogote,
Una percha en el escote

Bajo la nuez.

Chueca, vestida de pebeta,

Teñida y coqueteando

Su desnudez.

Pese a su glamour escenográfico, el cabaret se instaló en el mismo universo prostibulario que la academia y el peringundín. Un cambio de ropajes y de actitudes no alcanzaba para diferenciarlo de sus antepasados pobres, con 
quienes convivía. La mujer prostituida parecía ser el infausto común denominador. Cadícamo estableció la conexión con la misma metáfora del fango moral, haciendo referencia al tango de Pascual Contursi. Su título fue, simplemente, Cabaret.

$$
\begin{aligned}
& \text { Con pintoresco arramango } \\
& \text { qué bien canta... se diría } \\
& \text { que es tu propia biografía } \\
& \text { la letra de "Flor de fango". }
\end{aligned}
$$

Tanto el Royal Pigall como el Armenoville Les Ambassadeurs fueron definidos como centro de operaciones de una red de prostitución organizada, integrada por miembros de la mafia marsellesa en Buenos Aires. "La fuente de información (...) no procede de archivos policiales sino de boca de algunos músicos de tango ya desaparecidos". La red, según el famoso cantor y bandoneonista Juan Canaro, era dirigida por Alejandro y María Lombard, dos maquereaux nacidos en Córcega y llegados al país a finales del siglo XIX. La fachada que ocultaba el tráfico de mujeres habría sido una agencia de representantes artísticos para América Latina, con filiales en Santiago de Chile, Río de Janeiro y Buenos Aires. (Cadícamo, [1983]1999: 55).

En el año 1935, abrió sus puertas el cabaret Marabú. Estaba en Maipú 359, entre Sarmiento y Corrientes. Un joven Anibal Troilo hizo allí su debut en 1937. Fue el último de los grandes cabarets porteños. En 1936, una ley nacional prohibió los prostíbulos. Las casas de tolerancia se fueron de la ciudad y emigraron, de forma ya inevitablemente clandestina, a ciertas zonas de los alrededores. Muchos de los grandes cabarets siguieron funcionando por décadas, pero en general no sobrevivieron a los poderosos cambios culturales de la década de 1960. El ciclo de aquellos verdaderos "templos del tango" había concluido mucho tiempo antes.

\section{PALABRAS FINALES}

Las imágenes del tango Agua Florida son las primeras notas de una sinfonía compleja e inconclusa. La recuperación de ciertos lugares de diversión de Buenos Aires y su relación con el tango, puede generar algunos puntos de vista desde donde mirar parte de su historia urbana y su historia social. Todo este período, con un comienzo y un final borrosos puede ser, no obstante, comprendido en los inicios del tango de los primeros años y sus lugares de canto y baile, enfrentado con el proyecto de ciudad moderna. La trilogía constituida por sitio-letrabaile, fue ganando el centro desde el borde, desde lo clandestino hacia lo consagrado.

Entre las últimas dos décadas del siglo XIX y durante las tres primeras del siglo XX es posible definir cierta periodización de los lugares de diversión nocturna de la entonces reciente capital argentina, aunque una verdadera territorialización puede resultar más difusa. En el primer período, podríamos hablar de espacios "criollos", elementales, cuya principal 
característica fue la indeterminación funcional y la implantación periférica. Antes de que concluya el siglo, y con el objetivo de sortear los reglamentos, las redadas policiales y las inspecciones municipales, los bordes urbanos habían generado un particular dispositivo nocturno. Era habitual que las academias de baile, con esas chinas "que se metían en la vida a punta de corazón", funcionaran con despachos de bebidas y casas de tolerancia, conformando los tres elementos de aquel particular mecanismo que accionaba la diversión nocturna de la ciudad.

Luego, hacia el Centenario, surgen otras formas de entretenimiento masculino, como los cafés conciertos, los cantantes y de camareras. Estos espacios, si bien no pierden nunca cierto grado de indeterminación, pueden pertenecer a un segundo período "inmigrante", connotados por las costumbres de la enorme diversidad de pueblos que llegan a la ciudad y sus alrededores. Un tercer período, "internacional”, puede reconocerse en un doble sentido. Por un lado, la influencia de las imágenes que llegan especialmente del cine, sonoro a comienzos de la década de 1930, determinó espacios cinematográficos. Por el otro, la exportación e instalación del tango en grandes ciudades de Europa y de los Estados Unidos. Los escenográficos cabarets de la década de 1920 fueron los mayores exponentes de aquella etapa final.
En toda esta trayectoria propuesta, el peringundín se mantiene como el gran sobreviviente, que elude cualquier categoría espacial y se proyecta como alternativa, hasta prácticamente nuestros días. Acaso sea el mejor ejemplo de todos estos lugares, que muchas veces fueron más categorías imaginadas que espacios concretos. No obstante, todos ellos comparten cierta simetría en la conflictiva relación que mantuvieron con reglamentos y disposiciones. Sus escasas o nulas legalidades durante todo el tiempo analizado, pueden ser observadas, desde la academia de baile orillera, hasta el cabaret del centro. El fango termina por fusionar un único bajo fondo moral. Cualquier lugar de la ciudad podía, de esta forma, asimilarse a la imagen de una calle de tierra, después de una larga noche de lluvia.

Aún así, reconocemos la imposibilidad de reducir estos lugares a categorías específicas. Más bien intentamos una operación de síntesis para comprender un universo inmanejable, en sus glorias y en sus miserias. Los lugares del tango permiten revisar la historia de la ciudad, como una categoría ideológica, que implica exponer imaginarios que se superponen y a veces contradicen las lógicas de la ciudad material. Una serie de adaptaciones y de traducciones conceptuales constituyeron una cultura particular, alterna a los cánones de los principios establecidos por las elites dirigentes a la que ella, paradójicamente, contribuyó a difundir. Esta interpretación nos enfrenta al verdadero desafío de escribir una historia de la noche de Buenos Aires. 


\section{BIBLIOGRAFÍA}

\section{FUENTES PRIMARIAS}

ARLT, R. ([1929] 1997), Los siete locos. Buenos Aires: Editorial Altamira.

([1929] 2013) Aguafuertes porteñas, Buenos Aires: Losada

ALIFANO, R. (2011), Tirando manteca al techo (vida y andanzas de Macoco de Alzaga Unzué), Buenos Aires: PROA Amerian Editores.

BATIZ, A. ([1908] c.1960), Buenos Aires, la ribera y los prostíbulos en 1880. Contribución a los estudios sociales (libro rojo), Buenos Aires: Editorial Aga Taura.

BILBAO, J. (1926), Prostitución. Recopilación de ordenanzas, decretos, dictámenes, disposiciones de carácter interno etc. etc. En esta materia para exclusivo uso del personal de esta Inspección General, Buenos Aires: Municipalidad de la Ciudad.

BORGES, J. L. ([1927] 1997), "Hombre de la esquina rosada", Historia universal de la infamia, Obras Completas, Tomo 1, Buenos Aires: Emecé.

(1974), "Yo quería ser el hombre invisible”, reportaje por María Ester Gilio. Revista Crisis, Mayo de 1974, págs. 40-47.

CADíCAMO, E. ([1969]1973), Café de camareras. Buenos Aires: Editorial Sudamericana.

([1983]1999), Mis memorias. Buenos Aires: Corregidor.
DEPARTAMENTO DE POLICÍA DE LA CAPITAL (1880-1886), Memorias del Departamento de Policía de la Capital (MDP), Buenos Aires.

GÁLVEZ, M. ([1919] 1933), Nacha Regules, Buenos Aires: Editorial Tor.

INCHAUSPE, P (1942), Voces y Costumbres del Campo Argentino, Buenos Aires: Santiago Rueda Editor.

LUGONES, L. (1916), El payador, Buenos Aires: Otero \& Co. Impresores.

Merk's Manual of the Materia Medica (1899), Merk \& CO. New York (edición facsimilar).

MUNICIPALIDAD DE LA CAPITAL (1880-1925), Memorias de la Intendencia Municipal, varios números, Buenos Aires: edición oficial.

PUCCIA, E. (1976), El Buenos Aires de Angel G. Villoldo, 1860-1919, Buenos Aires: S/E.

SOLIÑO, V. (1967), Mis tangos y los atenienses, Montevideo: Libros Populares Alfa.

\section{FUENTES SECUNDARIAS}

CARIDE BARTRONS, H. (2017a), Lugares de mal vivir. Una historia cultural de los prostíbulos de Buenos Aires, 1875-1936. Buenos Aires: Instituto de Arte Americano e Investigaciones Estéticas “Mario J. Buschiazzo, FADU UBA.

(2017b), "Cenizas de orquídeas. Relatos del bajo fondo de Buenos Aires a comienzos del siglo XX". Anales $N^{\circ} 46$ Viajeros y ciudades. Buenos Aires: Instituto de Arte Americano e Investigaciones Estéticas “Mario 
J. Buschiazzo", FADU, UBA,

(2015), “El infame Paseo de Julio. Imaginarios prostibularios de Buenos Aires", Horacio Caride Bartrons. En Metáforas en pugna: estudios sobre los imaginarios del habitar, Mario Sabugo (director), Buenos Aires: Diseño Editorial.

CASADEVALL, D. (1957), El tema de la mala vida en el teatro nacional. Buenos Aires: Editorial Kraft.

LEGIDO, J.C. (1994), La orilla oriental del tango, Historia del tango uruguayo. Montevideo: Ediciones del Plata.

MATALLANA, A. (2016), El tango entre dos Américas. Representaciones en Estados Unidos durante las primeras décadas del siglo XX. Buenos Aires: Eudeba.

MAZZUCCHELLI, A. (2016), “Hombre de la esquina rosada: traducir el límite", publicación digital https://www.academia.edu/37917500/ (Consultado el 29-10-2019).

PUJOL, S. (1999), Historia del baile. De la milonga a la disco, Buenos Aires: Emecé Editores.

SABUGO, M. (2013), Del barrio al centro. Imaginarios del habitar en las letras del tango rioplatense. Buenos Aires: Café de las ciudades.

SARLO, B. ([1988] 1999), Una modernidad periférica: Buenos Aires 1920 y 1930. Buenos Aires: Nueva Visión.

ROCCA, P. (2010), “Duelos: sobre 'Hombre de la esquina rosada' e 'Historia de Rosendo Juárez', de Jorge Luis Borges y 'Gaucho pobre', de Enrique Amorim", Orbis Tertius Vol. $15 \mathrm{~N}^{\circ}$ 16. http://www.orbistertius.unlp.edu. ar (Consultado el 29-10-2019).

TALLÓN, J. (1964), El tango en sus etapas de música prohibida. Buenos Aires: Instituto de Amigos del Libro Argentino.

VARELA, G. (2016), Tango y política. Sexo, moral y revolución en Argentina. Buenos Aires: Ariel Historia.

\section{FUENTES DE LAS IMÁGENES}

Figura 1: Elaboración propia sobre el plano de H. Domengé y L. Broquá de 1874, en base a datos de la Memoria del Departamento de Policía, 1880-1881:227- 231 y de la Memoria de la Intendencia Municipal, 1893-1894:173175.

Figura 2: Revista Fray Mocho Año V, $\mathrm{N}^{\circ} 235$, del 10 de noviembre de 1916: 19 y 20.

Figura 3: Elaboración propia sobre el plano de H. Domengé y L. Broquá de 1876, en base a datos del Archivo Histórico Municipal, legajos 42-1885 Salud Pública; 130 - 1887 Salud Pública y 131 - 1887 Salud Pública.

Figura 4: Fotografía del Archivo General de la Nación.

Figura 5: GEOPE. Compañía de construcciones Sociedad Anónima (c.1929), lámina 44. 
68 Anales de Investigación en Arquitectura Vol.9 (2), 2019. Montevideo (Uruguay), 45-68 Universidad ORT Uruguay - ISSN 2301-1513 (en línea) 